\title{
Das águas de Callao para a praça de Lima: Monumento Dos de Mayo (1874)
}

\author{
Rafael Dias Scarelli'
}

DOI 10.20396/eha.vil4.3411

Em 29 de julho de 1874, foi inaugurado em Lima o Monumento Dos de Mayo, obra do escultor Louis-Léon Cugnot (1835-1894) e do arquiteto Edmond Cuillaume (1826-1894), ambos de nacionalidade francesa. Trata-se do terceiro monumento público erigido na capital peruana, antecedido pelo Monumento a Simón Bolívar, inaugurado em 1859, e pelo Monumento a Colón, inaugurado em $1860 .^{2}$

Dito monumento homenageia o triunfo militar de uma aliança de quatro repúblicas sulamericanas - Peru, Chile, Equador e Bolívia - sobre a esquadra espanhola, alcançado no Combate de Callao, em 2 de maio de $1866 .{ }^{3}$ Dessa feita, a obra se compõe de uma coluna rostral de mármore de aproximadamente vinte metros de altura, encimada por uma estátua que alegoriza a Vitória, em bronze. Junto ao pedestal da coluna, em cada uma de suas faces, estão dispostas estátuas em bronze que representam os quatro países aliados, além da figura do coronel José Cálvez (1819-1866), - Secretário de Guerra do Peru que morreu durante o combate - aos pés da estátua do Peru.

Esta comunicação pretende abordar o esforço empreendido pelas autoridades peruanas em garantir visibilidade internacional ao Monumento Dos de Mayo, organizando o concurso de projetos em Paris e garantindo sua presença em exposições europeias durante sua execução. Nosso conjunto de fontes se compõe, sobretudo, da documentação consular, especialmente a correspondência oficial entre as autoridades peruanas e a Legação peruana na França - localizada no Archivo del Ministerio de Relaciones Exteriores del Perú-, bem como dos artigos publicados na imprensa francesa durante a execução das obras - localizados por meio da Gallica/ Bibliothèque nationale de France.

\footnotetext{
1 Mestre em História Social pela Universidade de São Paulo, sob orientação da professora Dra. Gabriela Pellegrino Soares, com dissertação intitulada Nos altares da pátria: Monumento al Combate Dos de Mayo e Monumento a Francisco Bolognesi em Lima (1866-1924). Esta pesquisa foi financiada por uma bolsa concedida pela FAPESP e CAPES (processo FAPESP n ${ }^{\circ}$ 2017/05623-7, Fundação de Amparo à Pesquisa do Estado de São Paulo). As opiniões, hipóteses e conclusões ou recomendações expressas neste material são responsabilidade do autor e não necessariamente refletem a visão da FAPESP. Contato: rafael.scarelli@usp.br.

2 VIFIAN, Daniel. Escultura civil público estatal en Lima de 1852 a 1860. Lima: UNMSM, 2014.

3 Sobre esse conflito, um relato detalhado de suas causas e evolução pode ser encontrado em BASADRE, Jorge. Historia de la República del Perú, v. 1, 1822-1866. $3^{\circ}$ Ed. Lima: Editorial Cultura Antártica, 1946, pp. 385-421.
} 


\section{concurso}

Em 3 de maio de 1866, no dia seguinte ao Combate de Callao, o então presidente coronel Mariano Ignacio Prado (1825-1901) lançou o decreto que é o ponto de partida para construção do monumento, determinando que "en el lugar que el gobierno designará oportunamente, se erijirá [sic] un monumento consagrado á perpetuar la memoria del hecho de armas de 2 del presente". ${ }^{4}$

Dando cumprimento ao decreto presidencial, o Secretário de Governo José María Químper (1828-1902) lançou, em junho do mesmo ano, a primeira versão das bases do concurso para eleição do artista que ficaria encarregado da obra. Nesse documento, já transparecia o esforço por assegurar visibilidade internacional para o projeto e, consequentemente, para o futuro monumento. Químper transmitiu as bases ao Secretário de Relações Exteriores Toribio Pacheco, orientando-o a enviá-las ao ministro peruano na França, para que o concurso fosse convocado naquele país:

Sr. Secretario de Estado en el Despacho de Relaciones Exteriores. Para dar cumplimiento al supremo decreto dado en la ciudad del Callao el día 3 del mes próximo pasado, disponiendo que se erija [sic] un monumento consagrado á perpetuar la memoria del combate del 2 de mayo y hacer imperecedero el recuerdo de los ciudadanos que murieron en tan memorable dia [sic], US. se servirá ordenar al Sr. Ministro Plenipotenciario de la República en Francia, que, convoque á [sic] los artistas á [sic] un concurso público para que la ejecuccion [sic] del indicado monumento se conceda al estatuario que obtenga el primer prémio [sic]. El concurso puede establecerse bajo las bases siguientes [...]. ${ }^{5}$

Além de organizar a convocatória do concurso na França, as bases lançadas por Químper determinavam que o certame seria realizado na própria cidade de Paris: "Se fijará el plazo de un año para el término del concurso, y el lugar de su decisión será París" [grifo nosso]. O documento já indicava que a comissão julgadora do concurso seria formada pelo pintor de história suíço Marc Gleyre (1806$1874)^{6}$, associado a dois escultores e dois arquitetos de crédito. ${ }^{7}$

Para organizar o concurso e assessorar os artistas que se candidatassem, o governo peruano designou o diplomata e escritor de origem equatoriana Numa Pompilio Llona (1832-1907) como

\footnotetext{
4 El Peruano: publicación oficial. Lima, ano 24, tomo 50, semestre 1, n. 40, 4 de maio de 1866. Instituto Riva-Agüero (IRA). As citações em espanhol são transcrições exatas das fontes; as citações em francês foram traduzidas para o português.

5 El Peruano: Publicación Oficial. Lima, ano 24, tomo 51, semestre 2, n. 2, 7 de julho de 1866. IRA.

6 Marc Cleyre foi mestre do pintor peruano Francisco Laso na década de 1840. Informações sobre sua biografia podem ser encontrados no dossiê de uma exposição do Musée Cantonal des Beaux-Arts Lausanne. Cf. Charles Gleyre (1806-1874), le génie de l'invention, $n^{\circ}$ 9, 2006. Disponível: https://www.bcu-lausanne.ch/wp-content/uploads/2013/05/dp-09.pdf Acessado: 03.04.2019.

7 Segundo consta na ata dos jurados que distribuiu os prêmios do concurso, integraram a comissão julgadora, além de Gleyre, os arquitetos Eugène Violett-le-Duc e Jacques Félix Duban, membros do Instituto de França; e os escultores, também membros do Instituto, Eugène Guillaume - diretor da École des Beaux-Arts - e Jean-Joseph Perraud. Cf. Ofício de Francisco de Rivero ao MRE do Peru. Paris, 29 de fevereiro de 1868. Archivo Ministerio de Relaciones Exteriores (AMRE), caixa 178, carpeta 2, código 5-14-, Fólio 37 a 41.
} 
comissionado especial em Paris. Após um prolongado período de negociações, intermediadas por Llona, entre as autoridades peruanas e o pintor Gleyre, a respeito do conteúdo final das cláusulas da convocatória do concurso, as bases foram finalmente lançadas em fins de 1867. Uma vez definido o conteúdo do edital, o Ministro peruano na França Francisco de Rivero assim se dirigiu ao Ministério de Relações Exteriores:

Tengo la honra de comunicar a US. que con fecha 23 del actual he dado orden a la Casa de Thomas La Chambe y $C^{a}$. para que entreguen a D. Numa Pompilio Llona la cantidad de Setecientos francos destinados á costear los gastos de publicidad del programa del monumento del 2 de Mayo en los diarios de Francia, Alemania, Belgica é [sic] Italia. El objeto de esta publicacion [sic] no solo es el de convocar artistas para el concurso que con arregloá [sic] las resoluciones supremas espedidas [sic] sobre este particular tiene que abrirse, sino tambien [sic] el de dar á [sic] conocer el espíritu bajo del cual debe ser concebido el plan del espresado [sic] monumento para simbolizar el grandioso suceso del que esta llamado á [sic] perpetuar la memoria. [grifo nosso] ${ }^{8}$

Dessa feita, as bases do concurso foram divulgadas em diversos periódicos europeus - a exemplo dos jornais franceses La Chronique des Arts, Le Figaro e Le Presse ${ }^{9}$-, acrescentando-se o endereço do comissionado Llona em Paris, quem os candidatos poderiam procurar se desejassem maiores informações sobre o certame. Inscreveram-se 36 artistas europeus - a maioria franceses, entre os quais o escultor Frédéric Bartholdi, que depois se destacaria pela estátua da Liberdade em Nova York, e o arquiteto Gabriel Davioud, autor da Fontaine de Saint-Michel e do desaparecido Palais du Trocadéro. $^{10}$

Para exibição dos projetos concorrentes ao público, a Legação do Peru na França conseguiu o empréstimo de uma sala do Palácio das Indústrias. Em ofício dirigido ao governo peruano em fevereiro de 1868, Albertini, membro da Legação, comunicou que:

[...] una localidad especial nos ha sido designada para este fin en el Palacio de la Industria, [...]. La exposicion [sic] pública de los proyectos tendrá lugar el 17 al 22 del presente mes en cuya ultima fecha se reunirá el jurado llamado a clasificarlos, conforme el decreto supremo de la materia que nos ha sido oportunamente comunicado". ${ }^{11}$

8 Ofício número 340, de Francisco de Rivero para o MRE. Paris, 30 de outubro de 1867. AMRE, caixa 171; carpeta 2; código 5-14; fólio 137.

9 La Chronique des Arts et de la Curiosité: supplément a la Gazette des Beaux-Arts. "Exposition et Concours". Paris, $n^{\circ}{ }^{198}, 10$ de novembro de 1867, pp. 260-261; Le Figaro. "Un monument a faire". Paris, ano 14, nº 189, 24 de maio de 1867, p. 3; La Presse. "Avis divers". Paris, ano 32,28 de abril de 1867, p. 3. BnF-Gallica.

10 A obra produzida pela Sociedad Fundadores de la Independencia Vencedores el 2 de Mayo, comemorativa ao $75^{\circ}$ aniversário do Combate de Callao, publicada em 1941, apresentou uma lista dos artistas que participaram do certame. Sociedad "Fundadores [...]" (ed.). El 75 aniversario del glorioso Combate del 2 de Mayo de 1866. Lima: Ministerio de Guerra, 1941, p. 353.

11 Ofício $n^{\circ}$ 119/868, assinado por Albertini, Legación del Perú en Francia, ao MRE do Peru. Paris, $1^{\circ}$ de fevereiro de 1868. AMRE, caixa 178, carpeta 2, código 5-14-, fólio 29. 


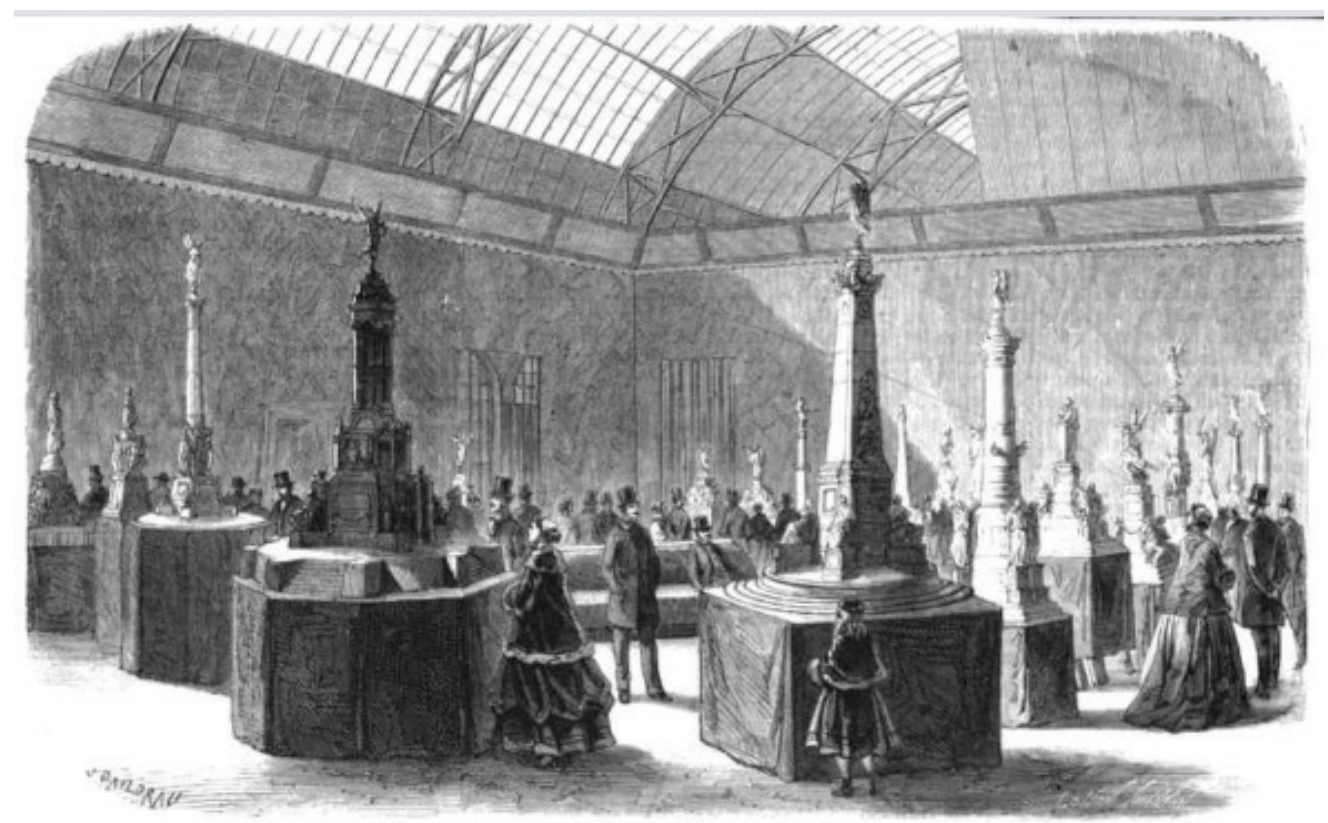

[Figura 1] Exposição dos projetos em fevereiro de 1868.

Lillustration. "Exposition des modèles du monument a élever au Pérou", Paris, ano 26, vol. 51, $n^{\circ} 1305,29$ de fevereiro de 1868 , p. 138.

[Figura 2]

L'Univers Illustré, $n^{\circ} 902$. Paris, 6 de julho de 1872 , p. 428

Fonte: BnF-Callica, http://gallica.bnf.fr/ark:/12148/ bpt6k5757942p/f6.item Acessado: 08.06.2017.

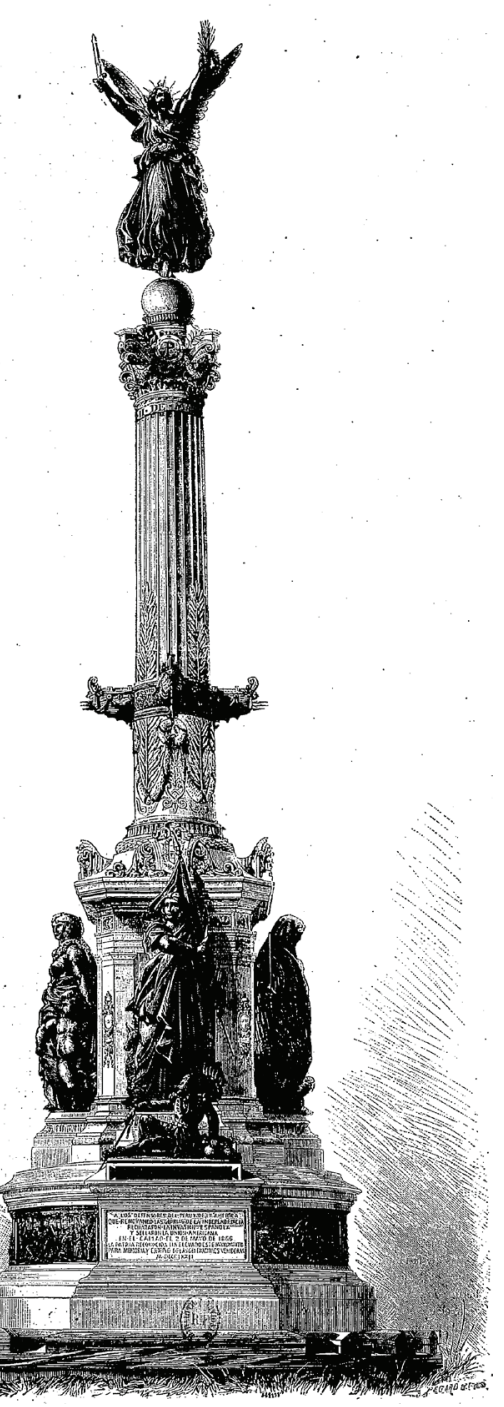


Nessa ocasião, foi publicada no periódico francês L'Illustration uma gravura dos projetos em exibição, cercados pelo público, única fonte visual de que dispomos da referida exposição (figura 1). Após a reunião da comissão julgadora, foi outorgado o primeiro prêmio ao projeto 21 Patrie et Liberté, da dupla Cugnot e Guillaume.

\section{Exposições internacionais}

Ao longo do processo de execução das obras do monumento em Paris houve o esforço de garantir a exibição de suas partes concluídas em exposições internacionais de arte. Contudo, tal esforço partiu mais das autoridades peruanas na França - em contato com os circuitos expositivos e artísticos europeus e em relação direta com os artistas vencedores -, do que das autoridades no Peru - desejosas de conter despesas, pressionadas pela crise econômica resultante da diminuição das exportações de guano, o que levaria o país a declarar a moratória de sua dívida externa em $1876 .{ }^{12}$

O primeiro registro que localizamos de tal esforço data de julho de 1870. Em correspondência com o Ministério das Relações Exteriores, o ministro peruano na Inglaterra e França Pedro Gálvez, a respeito do estado adiantado das obras, dizia: "he podido admirar la estatua del Perú que figuró en la ultima exposicion [sic] de Bellas Artes y que, en mi concepto, es de un exquisito trabajo artístico" [grifo nosso] ${ }^{13}$. De fato, podemos encontrar uma menção à estátua do Peru no catálogo do Salão de 1870.

CUCNOT (León) nascido em Vaugirard (Paris), aluno de Duret e Diébolt. Fora de competição. Boulevard de Grenelle, 17. 4396-A República do Peru defendendo sua independência; estátua, bronze (Para o monumento a ser erigido em Lima, em comemoração à vitória do 2 de maio de 1866). ${ }^{14}$

No ano seguinte, o ministro Pedro Cálvez, em ofício ao Ministério no Peru datado de 27 de junho de 1871, afirmava que fotografias da obra haviam sido enviadas a Londres para participarem de uma exposição:

Ya que nos sea posible exibir [sic] en Paris, como habria [sic] sido de desear el Monumento íntegro, lo que le habria [sic] dado gran crédito, que habria [sic] recaído sobre el Perú, procuro al menos que se exiba [sic] en fotografias [sic]. Algunas de estas estan [sic] yá [sic] en Londres y he autorizado al

\footnotetext{
12 CONTRERAS, Carlos; CUETO, Marcos. Historia del Perú Contemporáneo: Desde las luchas por la Independencia hasta el presente. Edição digital, Lima: IEP, 2013, p. 162 (1 ${ }^{\text {a }}$ ed. 1999).

13 Ofício de Pedro Gálvez, ao MRE. Paris, 16 de julho de 1870, anexa carta de N. Llona. AMRE, caixa 194, carpeta 2, código 5-14-, fólios 111 a 114.

14 Tradução do autor. Ministère des Beaux-Arts. Salon de 1870. $88^{\circ}$ Exposition Officielle. Paris: Charles de Mourgues Frères, imprimeurs des musées impériaux, 1870, p. 581. Edição digitalizada: Paris Salon de 1870. Garland Publishing, Inc. New York \& London, 1977.
} 
Consúl [sic] para que arregle con el Director de la Exposicion [sic] el modo mejor de exibir [sic] esta obra de arte. ${ }^{15}$

Em setembro do mesmo ano, o ministro, em novo ofício, volta a mencionar essa exposição, sobre a qual oferece mais detalhes. Ao anunciar que as primeiras peças da obra logo chegariam ao Peru - cobrando das autoridades peruanas a definição de qual seria o local de implantação do monumento na capital peruana -, Gálvez informa que fotografias tomadas dos bronzes já concluídos haviam sido expostas na Exposição Internacional de Londres, recebendo elogios. ${ }^{16}$

O momento mais destacado desse esforço de exibição veio em 1872, com a exposição de um simulacro da obra completa, montado com suas partes já concluídas, na Exposição Universal de Paris de 1872. Mais uma vez, tal iniciativa partiu da Legação na França, encontrando resistência entre as autoridades no Peru, que ansiavam pela rápida conclusão e inauguração da obra em Lima, bem como conter gastos, como podemos averiguar no ofício enviado a Paris:

[...] Digo á [sic] Us. que el gobierno no estima como conveniente la exhibición del citado monumento por que a mas [sic] de retardarse con esto su remision [sic] del Perú ocasiona gastos que han debido evitarse en las circunstancias en que se encuentra el Erario Nacional y por hallarse prohibido hacerse gastos extraordinarios sin previa autorización del gobierno. ${ }^{17}$

Contornando a resistência, a obra foi incluída na exposição, instalada em um local privilegiado, diante da porta principal do Palácio das Indústrias, como revela o catálogo do Salão:

CUGNOT (Louis-Léon), nascido em Paris, aluno de Duret e de Diébolt. Fora de competição. Boulevard de Grenelle, 67. [...]. 1628 - Monumento comemorativo à vitória em Callao, em 2 maio de 1866, pelos peruanos sobre a Esquadra Espanhola. Seis episódios do combate; - baixos-relevos, bronze. Na face anterior, o coronel Galvez expia aos pés do Peru, sua pátria; - estátua, bronze. Nas outras faces, as Repúblicas do Chile, do Equador e da Bolívia; —estátuas, bronze. Na coluna, a República peruana vitoriosa; — estátua, bronze dourado (Obtido por concurso). (Exposto fora do Palácio, em frente à porta principal). ${ }^{18}$

Por sua vez, o periódico francês L'Univers Illustré apresentou aos leitores uma detalhada descrição das partes do monumento, revelando a preocupação pelo correto entendimento da obra por parte do público. Esse jornal reafirmou também a localização da coluna na exposição e ainda men-

\footnotetext{
15 Ofício n. 118, de Pedro Gálvez ao MRE. Londres, 27 de junho de 1871. AMRE, caixa 201; carpeta 1; código 5-17; fólios 77, 75 e 76.

16 Ofício n 52, de Pedro Gálvez ao MRE. Paris, 25 de setembro de 1871. AMRE, caixa 200, carpeta 11, código 5-14, fólios 118-119.

17 Ofício de Manuel de Santamaría. Lima, 13 de junho de 1872. AMRE, caixa 205, carpeta 7, código 2-0.

18 Tradução do autor. Ministère de L'Instruction Publique, des Cultes et des Beaux-Arts. Salon de 1872. 89 Exposition Officielle. "Sculpture gravure en médailles et en pierres fines”. Paris: Imprimerie Nationale, 1872. Edição utilizada: Paris Salon de 1872. New York \& London: Garland Publishing, Inc, 1977, p. 249.
} 
cionou a boa recepção à obra, destacados em negrito no trecho transcrito a seguir:

Esta coluna triunfal foi executada após um concurso aberto em Paris pelo governo peruano, no qual o primeiro prêmio foi concedido ao senhor Louis Cugnot. O trabalho de Cugnot figura na exposição de belas artes de 1872; foi erigido em frente à porta principal do Palácio das Indústrias e, por seu belo ordenamento, mereceu os sufrágios do público. Ao topo da coluna, uma vitória alada, em bronze dourado, parece pronta para saltar no ar. Ao redor da coluna, são colocadas as estátuas de bronze das quatro repúblicas aliadas: Peru, Chile, Bolívia e Equador. Aos pés da estátua do Peru, vemos a estátua do coronel Gálvez dando sua vida pela santa causa da pátria. Seis baixos-relevos de bronze retratam episódios do Combate de Callao [grifo nosso]. ${ }^{19}$

Foi no contexto dessa exposição, realizada dois anos antes da inauguração da obra escultórica em Lima, que circularam as primeiras fotografias e gravuras do monumento montado. Nas próprias página do jornal L'Univers Illustré (figura 2), bem como no jornal El Americano, gravuras representando a obra foram publicadas. Igualmente, como já apresentou o trabalho da historiadora peruana Natalia Majluf, foram tomadas fotografias do simulacro da coluna diante da porta do Palácio, posteriormente remetidas ao Peru. ${ }^{20}$

Buscava-se, organizando o concurso em Paris e incluindo a obra em exposições internacionais, garantir visibilidade ao projeto e, consequentemente, afirmar o "progresso" alcançado pelo Peru às nações europeias. Contudo, tal estratégia também amargou adversidades, uma vez que durante a execução do monumento, entre março e maio de 1872, eclodiu a Comuna de Paris, exigindo que o comissionado Llona abandonasse a capital francesa por um período. ${ }^{21}$

\footnotetext{
19 Tradução do autor. Cf. L'Univers Illustré. "Bulletin”. Paris, n 902, 6 de julho de 1872, p. 422. Cf. BnF-Callica.

20 MAJLUF, Natalia. Escultura y espacio público. Lima, 1850-1879. Lima: IEP, 1994, p. 52.

21 Llona solicitou posteriormente uma indenização ao governo peruano, pelos gastos ocasionados por sua retirada de Paris. Ofício de Manuel de Santamaría ao MRE. Lima, 15 de janeiro de 1872. AMRE, caixa 205, carpeta 7, código 2-0-, fólio 7.
} 


\section{Referências Bibliográficas}

BASADRE, Jorge. Historia de la República del Perú, v. 1, 1822-1866. $3^{\circ}$ Ed. Lima: Editorial Cultura Antártica, 1946.

CASTRILLÓN, Alfonso. "Escultura Monumental y funeraria en Lima”. In: Escultura en el Perú. Lima: Editorial BCP, 1991. CONTRERAS, Carlos; CUETO, Marcos. Historia del Perú Contemporáneo: Desde las luchas por la Independencia hasta el presente. Edição digital, Lima: IEP, 2013, p. 162 (1ª ed. 1999).

GODOY ORELLANA, Milton. "Ha traído hasta nosotros desde territorio enemigo, el a laud de la guerra: confiscación de maquinarias y apropriación de bienes culturales durante la ocupación de Lima, 1881-1883", Historia, n 44, vol. 2, jul.-dez. de 2011, pp. 287-327.

GUTIÉRREZ VIÑUALES, Rodrigo. Monumento conmemorativo y espacio público en Iberoamérica. Madrid: Cátedra, 2004.

KNAUSS, Paulo. "Introdução". In: KNAUSS, Paulo (coord.). Cidade vaidosa: imagens urbanas do Rio de Janeiro. Rio de Janeiro: Sette Letras, 1999.

LLONA, Teresa María. Numa Pompilio Llona y el monumento 2 de mayo. Lima: s.n., 1966.

MAJLUF, Natalia. Escultura y espacio publico. Lima, 1850-1879. Lima: IEP, 1994.

MONTEIRO, Michelli. São Paulo na disputa pelo passado: Monumento à Independência de Ettore Ximenes. São Paulo: tese de doutorado - FAU-USP, 2017.

MONTEVERDE SOTIL, Rodolfo. "El monumento al Combate del 2 de Mayo en Lima: un símbolo americanista frente a España, 1866-1874". Procesos, n. ${ }^{\circ}$ 49, jan.-jun. 2019, pp. 39-75.

SOARES, Gabriela Pellegrino. Projetos políticos de modernização e reforma no Peru: 1950-1975. São Paulo: Annablume/ FAPESP, 2000.

Sociedad "Fundadores de la Independencia Vencedores el Dos de Mayo de 1866 y Defensores Calificados de la Patria". El 75 aniversario del glorioso Combate del 2 de Mayo de 1866. Lima: Ministerio de Guerra, 1941.

VIFIÁN LÓPEZ, Daniel. Escultura civil público estatal en Lima de 1852 a 1860. Lima: tese para obtener el título de Licenciado en Arte - FLCH-UNMSM, 2014. 